
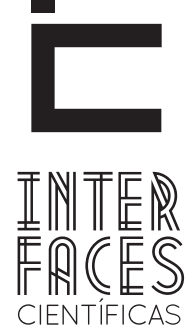

DIREITO

\title{
CRIMES AMBIENTAIS: UMA VISÃO SOBRE AS PRÁTICAS DO RODEIO E DA VAQUEJADA
}

Igor Macedo Brandão ${ }^{1}$

\section{RESUMO}

0 rodeio e a vaquejada são modalidades esportivas bastante difundidas no Brasil e que utilizam animais em seus eventos. Os animais utilizados são frequentemente submetidos à violência e maus tratos. 0 ordenamento jurídico brasileiro possui instrumentos que coíbem atos cruéis contra animais, porém a liberdade cultural, prevista constitucionalmente, por vezes ampara este tipo de prática. Considerando-se a necessidade de proteger o meio ambiente natural e a integridade física dos animais utilizados em eventos esportivos, como a vaquejada e o rodeio, percebe-se a necessidade de haver um maior rigor na elaboração da legislação ambiental voltada para defesa e proteção da fauna, além de se estabelecer um limite para a liberdade cultural, para que esta não se sobreponha ao bem estar dos animais.

\section{PALAVRAS- CHAVE}

Rodeio. Vaquejada. Maus Tratos. Crueldade. Cultura 


\section{ABSTRACT}

The rodeo and "vaquejada" are sports quite widespread in Brazil and who use animals in their events. The animals are often subjected to violence and abuse. The Brazilian legal framework has methods for repressing animal maltreatment, but the cultural freedom, provided in Constitution, sometimes, supports this practice. Considering the need to protect the natural environment and physical integrity of animals, used for sporting events, like the rodeo and "vaquejada", realizes the need for a greater rigor in the development of environmental legislation focused on defense and protection of wildlife, and to establish a threshold for cultural freedom so that it does not overlap with animal welfare.

\section{KEYWORDS}

Rodeo. “Vaquejada”. Maltreatment. Cruelty. Culture.

\section{RESUMEN}

Vacas de las cuerdas y el toreo son deportes que están muy extendidos en Brasil y que utilizan animales en sus eventos. Los animales a menudo son objeto de violencia y abuso. El sistema jurídico brasileño cuenta con instrumentos que restringen actos crueles contra los animales, pero la libertad cultural prevista constitucionalmente a veces sostiene este tipo de práctica. Teniendo en cuenta la necesidad de proteger el medio ambiente natural y la integridad física de los animales utilizados en eventos deportivos como el Toreo y los de Vaca a Cuerdas, uno se da cuenta de la necesidad de una mayor precisión en la redacción de la legislación ambiental, centrado en la defensa y protección de la fauna, además de establecer un umbral para que la libertad cultural no se superponga el bienestar de los animales.

\section{PALABRAS CLAVE}

Toreo. Vaca a Cuerdas. Maltratos. Crueldad. Cultura.

\section{INTRODUÇÃO}

São cada vez mais comuns no Brasil práticas esportivas que submetem animais a maus tratos. Neste artigo são analisadas duas dessas modalidades: o rodeio e a vaquejada. Mas, vale salientar que diversas outras também são praticadas, como, por exemplo, a rinha de galo, realizada em várias regiões do país e a "farra do boi", comum na região sul do país.

Inicialmente, tanto a vaquejada quanto o rodeio eram praticados apenas com fins culturais, porém, com o passar dos anos e com a profissionalização destas modalidades, o fator econômico passou a ser cada vez mais preponderante, já que muito dinheiro vem sendo investido. Com isso, a prática dessas modalidades se transformou em grandes even- tos festivos e os animais passaram a ser, também, mais exigidos, o que aumentou o nível de violência, crueldade e maus tratos cometidos contra eles. Mesmo assim a questão cultural é frequentemente colocada por seus praticantes como razão principal para a existência destas modalidades esportivas.

Este artigo objetiva lançar uma visão mais detalhada sobre o rodeio e a vaquejada, e sobre a relação entre essas modalidades e os animais utilizados por seus praticantes. Foi feito um levantamento histórico e uma caracterização das duas modalidades e, posteriormente, um enquadramento delas dentro do ordenamento jurídico ambiental brasileiro. 
A pesquisa procurou estabelecer uma diferenciação entre os aspectos culturais que envolvem as duas modalidades e as práticas cruéis contra os animais utilizados.

\section{MATERIAL E MÉTODOS}

Este estudo constitui-se de uma revisão da literatura especializada, realizada entre janeiro e novembro de 2012, na qual se realizou uma consulta a livros, periódicos e artigos científicos, selecionados por meio de buscas nos bancos de dados do Scielo, da Bireme e Google Scholar, além da legislação brasileira vigente e arquivo bibliográfico pessoal.

As palavras-chave utilizadas na busca foram rodeio, vaquejada, maus tratos, legislação ambiental e crimes ambientais.

\section{RESULTADOS E DISCUSSÃO}

\subsection{HISTÓRICO E CARACTERIZAÇ̃̃O DA VAQUEJADA}

A vaquejada é uma prática difundida amplamente na região Nordeste do Brasil, mas que há algum tempo vem ganhando espaço nas demais regiões brasileiras, principalmente por meio dos grandes eventos festivos que envolvem a modalidade e que estão sendo levados para diversas cidades.

\section{Segundo definição de Silva (2007):}

a vaquejada é uma "modalidade esportiva" praticada, sobretudo, no Nordeste brasileiro, na qual dois vaqueiros a cavalo devem derrubar um boi, dentro dos limites de uma demarcação a cal, puxando-o pelo rabo. Vence a dupla que obtiver maior número de pontos.
Os critérios de inclusão para os estudos encontrados foram a caracterização do rodeio e da vaquejada, tanto como modalidades esportivas, quanto como manifestações culturais.

Em seguida, buscou-se estudar e compreender as principais características envolvendo as duas modalidades esportivas, bem como cada uma é tratada na legislação ambiental vigente.
E essa talvez seja a principal imagem que ilustra a modalidade: dois vaqueiros cercando um boi em um espaço delimitado, tentando derrubá-lo. 0 fato de haver uma perseguição ao animal, em um espaço cercado, com o intuito de levá-lo ao chão abruptamente já é uma prova de que tipo de tratamento é dispensado a estes animais.

Na vaquejada, cada vaqueiro tem um papel definido: um deles é o encarregado de derrubar o boi pelo rabo (vaqueiro-puxador), enquanto o outro (bate-esteira) dá apoio ao primeiro, no sentido de evitar que o boi saia do trilho da corrida, conquistando, assim, a pontuação desejada no torneio (MARASCHIN; ITAQUI, 2010) 
Além da divisão de tarefas entre os dois vaqueiros participantes, o grau de profissionalização e qualificação deles, também, apresenta uma divisão. Segundo Aires (2008, p. 15), na vaquejada as diferentes representações dos vaqueiros são constituídas pelos conhecidos "vaqueiro-puxador" e "bate-esteira", assim como pelas categorias denominadas: vaqueiro profissional e amador. Os profissionais são vaqueiros experientes nas competições, que utilizam a vaquejada como meio de sobrevivência. Já os amadores são aqueles que não têm a vaquejada como meio de vida, não recebendo, assim, a mesma qualificação dada ao vaqueiro profissional.

Historicamente, como afirmam Menezes e Almeida (2008, p. 182), a vaquejada é uma festa que teve origem no sertão nordestino, com a labuta na criação de gado, a partir da festa da apartação, constitui-se em uma representação cultural arraigada do sertanejo e é uma prática lúdica rural.

Mas, apesar das origens semelhantes, a vaquejada e a apartação tinham objetivos diferentes, como afirmam Menezes e Almeida (2008), já que a apartação era uma festa proporcionada pelo fazendeiro para tentar recompor seu rebanho, ou ocorria no momento de ferrar o gado para a comercialização, enquanto a vaquejada se originou com a procura dos animais bravios na caatinga; essas investidas, posteriormente, transformaram-se em rituais festivos, atraindo, no sertão, as comunidades próximas e as distantes. Da apartação do gado, nasceu uma festa rural que dominava em todo o sertão nordestino.

De acordo com Silva (2007), a vaquejada originou-se da necessidade de reunir o gado que era criado solto na mata na época dos coronéis, também com ponto de partida nas apartações. Baseando-se na afirmação deste autor, verifica-se que a festa da apartação precede a vaquejada, visto que após feita a separação do gado, os vaqueiros, então, tinham a oportunidade de mostrar sua habilidade em lidar com os cavalos e o gado, naquilo que receberia a denominação de "vaquejada".
Os coronéis e os senhores de engenho passaram então a organizar torneios de vaquejadas, onde os participantes eram os vaqueiros, e os patrões faziam apostas entre si, mas ainda não existiam premiações para os campeões, havendo apenas uma gratificação aos vaqueiros vencedores (SILVA, 2007).

Como é possível perceber, a prática da vaquejada à época das apartações é bem diferente do que se vê hoje. Antes ela era uma atividade de origem cultural, contendo aspectos lúdicos, inclusive. Porém, atualmente a prática vem ganhando cada vez mais um aspecto de esporte e competição, trazendo consigo grandes investimentos financeiros.

O que antes era uma "confraternização" entre coronéis, senhores de engenho e vaqueiros, hoje é uma verdadeira indústria. A vaquejada atualmente envolve não apenas o aspecto "esportivo", mas, também, grandes festas e feiras agropecuárias, que acabam se tornando argumentos a favor da vaquejada, por seus defensores, que afirmam que elas geram grandes investimentos financeiros, além de incrementar o turismo nas regiões onde é realizada, além de gerar empregos. Porém, quando se analisa o sofrimento a que são submetidos os animais, estes aspectos ficam em segundo plano.

\subsection{HISTÓRICO E CARACTERIZAÇ̃̃O DO RODEIO}

Para definir esta modalidade, utiliza-se a definição de Neves (2008, n.p.), ao afirmar que "dá-se o nome de rodeio à atividade de montaria em dorso de animal, em que o 'peão' (pessoa participante da prova) se propõe ao desafio de permanecer o maior tempo possível montado, enquanto o animal pula e se contorce na arena".

No Brasil, o rodeio, basicamente, é uma competição composta por diversas atividades de montaria em dorso de equinos, bovídeos e caprinos, bem como de captura desses animais, figurando como atração popular em exposições de bovinos e equídeos (SOUZA, 2008). 
0 rodeio possui algumas modalidades e estilos principais, e para demonstrar como são praticadas no Brasil, faz-se uso das palavras de Souza (2008, p. 2) ao afirmar que

\begin{abstract}
nos rodeios ocorridos no Brasil, verifica-se a predominância de duas modalidades de montaria: a de cavalo e a de touro. Na montaria em cavalo, há essencialmente três estilos. A diferença básica entre esses estilos está na utilização de diferentes equipamentos, os quais obrigam a mudança na forma da montaria. 0 primeiro, cutiano, é o estilo tipicamente brasileiro, no qual há o uso de sela, sedém e rédeas. No saddle bronc, utiliza-se sela americana sem pita. Por fim, há o estilo bareback no qual se utiliza também sela americana, porém esta bem é pequena e conta com alça para apoio da mão. Por outro lado, na montaria de touros usa-se, dentre outros apetrechos, o sedém e a peiteira, ajustados no corpo do animal e através da qual o peão se segura sobre o animal com uma das mãos.
\end{abstract}

Durante a prova de rodeio, o animal é amarrado por um instrumento chamado sedém (espécie de amarra, que aperta o dorso do animal, que em alguns casos tem seus órgãos reprodutivos esmagados para que pule com mais força). Enquanto isso, o peão permanece em cima do animal, sendo conferido o prêmio àquele que por mais tempo prolongar esta situação. Presencia o público acalorado a uma exibição da capacidade de humana de se comportar de modo cruel, crueldade esta que se mostra de forma mais clara quando o peão é louvacionado, como se tal atividade pudesse ser motivo de algum orgulho (NEVES, 2008).

Ao contrário da vaquejada, o rodeio não tem raízes brasileiras. Segundo Pimentel (2006, p. 93)

internacionalmente, os estudos sobre o rodeio nos países anglo-saxões o tomam como um esporte adaptado pelos norte-americanos, no século XIX, após intercâmbios com mexicanos. A partir de 1975, há uma pressão pela institucionalização do rodeio como esporte, evitando que a Humane Society of the United States (HSUS) obtivesse o embargo das competições. Não por menos as pesquisas nesse período enfocaram parâmetros biológicos a fim de identificar o estresse e os riscos que animais e cowboys estavam sujeitos. Nas décadas seguintes, os estudos em Medicina Esportiva firmaram- -se como forte tendência internacional na produção de conhecimento sobre rodeio, especialmente devido ao Prorodeo Sports Medicine, um programa patrocinado pela Justin, uma fabricante de botas.

Entretanto, embora já fossem freqüentes os trabalhos históricos sobre o rodeio desde 1920, os anos 1980 evidenciaram o questionamento sociocultural desta prática na sua roupagem esportiva, trazendo instigantes reflexões sobre relações de gênero, impacto econômico e significado cultural. Nos anos de 1990, considerando o status do rodeio como esporte radical e lucrativo, periódicos de sociologia, psicologia e filosofia do esporte retomam a discussão do risco e da violência nas competições.

Percebe-se que o rodeio há muito vem sendo questionado enquanto prática esportiva, devido aos riscos e violência que pode gerar. Mas, assim como a vaquejada (ou até em proporções maiores, também, por sua maior abrangência geográfica), o rodeio hoje é uma indústria de entretenimento que gera muito dinheiro ao seu redor, o que faz com que a integridade dos animais utilizados para sua prática seja colocada em segundo plano.

\subsection{LEGISLAÇÃO AMBIENTAL BRASILEIRA E PROTEÇÃO À FAUNA}

A proteção à fauna vem sendo tratada dentro do ordenamento jurídico brasileiro desde a década de 1930, com a proclamação do Decreto Federal 24.645/34, que vedava a prática de maus tratos a animais.

Em 1941 surge a tipificação da conduta da prática de crueldade contra animais no artigo 64 do Decreto-lei 3.688, conhecido como Lei das Contravenções Penais. Este artigo posteriormente ganharia status de crime ambiental na atual Lei 9605/98 (artigo 32), além de ter sido recepcionada pelo atual constituição nacional, promulgada em 1988 (art. 225 § 10, VII) (LEVAI, 2002, p. 101; CADAVEZ, 2008).

Como afirma Cadavez (2008), é importante salientar que o artigo 32 da lei de Crimes Ambientais não revogou o Decreto-lei 24.654/34, “mas veio a complementá-lo com dispositivos que visavam a proteção da fauna”. 
Em 1981 a Lei da Política do Meio Ambiente, lei 6.938 , definiu a fauna como recurso ambiental, disciplinando a ação governamental e inserindo a responsabilidade civil e administrativa pelo dano ambiental. Esta lei foi de grande importância para o desenvolvimento do Direito Ambiental brasileiro (CADAVEZ, 2008).

Em 1988 foi promulgada a atual Constituição Federal, que em seu artigo 225 afirma que,

Todos têm direito ao meio ambiente ecologicamente equilibrado, bem de uso comum do povo e essencial à sadia qualidade de vida, impondo-se ao Poder Público e à coletividade o dever de defendê-lo e preservá-lo para as presentes e futuras gerações.

A partir daí, o meio ambiente passou a ser tido como um bem tutelado juridicamente. Nesse mesmo artigo, em seu parágrafo $1^{\circ}$, inciso VII afirma que:

Para assegurar a efetividade desse direito, incumbe ao Poder Público proteger a fauna e a flora, vedadas, na forma da lei, as práticas que coloquem em risco sua função ecológica, provoquem a extinção de espécies ou submetam os animais a crueldade (BRASIL, 1988).

Analisando-se somente as constituições brasileiras, fica claro que somente em 1988 o meio ambiente passou a ser protegido de forma mais específica. Neste sentido, Cadavez (2008, p. 89) afirma que:

as Constituições Brasileiras anteriores à de 1988 não traziam a proteção do meio ambiente natural de forma específica. Das Constituições Brasileiras desde 1946 apenas havia uma orientação protecionista com relação à saúde e sobre a competência da União para legislar sobre a caça, a pesca, as florestas e a água. Já a atual Constituição Federal de 1988, deu um novo rumo à matéria relativa a fauna, entrando ela no texto constitucional como componente de ecossistemas e, portanto, como objeto de proteção. A Constituição da República promulgada em 1988 é uma Constituição "eminentemente ambientalista", sendo a primeira a tratar deliberadamente sobre a questão ambiental. É a primeira Constituição Brasileira que menciona a expressão "meio ambiente”, trazendo um capítulo específico sobre o assunto, mas também permeando todo o texto constitucional com a questão, correlacionandoa com seus temas fundamentais.
Em 1998 surge no cenário brasileiro a denominada Lei dos Crimes Ambientais, Lei 9.605, que, também, passou a tratar da proteção da fauna e que dispõe sobre as sanções penais e administrativas derivadas de condutas lesivas ao meio ambiente (CADAVEZ, 2008).

Analisando detalhadamente o artigo 32 da Lei 9605/98, percebe-se que não há permissão para experiências dolorosas ou cruéis em animais vivos, mesmo que sejam aplicadas para fins didáticos ou científicos, lembrando que há aumento da pena de um sexto a um terço, se ocorrer a morte dos animais, nas circunstâncias previstas no artigo (BRASIL, 1998).

Se nem mesmo para fins científicos ou didáticos práticas cruéis ou que causem sofrimento aos animais são permitidas, é de se imaginar que estas práticas também fossem reprimidas em se tratando de eventos esportivos ou de entretenimento, como é o caso do rodeio e da vaquejada.

A grande questão aqui é que os defensores das duas modalidades se baseiam nos aspectos culturais para não enquadrá-las como crimes ambientais. Para isso, eles recorrem à Constituição Federal da República de 1988, que em seu artigo 215 afirma que "o Estado garantirá a todos o pleno exercício dos direitos culturais e acesso às fontes da cultura nacional, e apoiará e incentivará a valorização e a difusão das manifestações culturais” (BRASIL, 1988).

Nesse ponto, percebe-se um conflito entre o meio ambiente natural e o meio ambiente cultural, surgindo a dúvida de, até que ponto uma manifestação pode se basear apenas em questões culturais para justificar a práticas de ações cruéis e/ou dolorosas contra animais (FIORILLO, 2006, p. 117).

Mas, como bem lembra Cadavez (2008, p. 97), o Supremo Tribunal Federal ao analisar a prática conhecida como "farra do boi”, que também submete os animais à crueldade, principalmente na região sul do Brasil, apoiando-se em aspectos culturais, afirmou que, 
a obrigação de o Estado garantir a todos o pleno exercício de direitos culturais, incentivando a valorização e a difusão das manifestações, não prescinde da observação da norma do art. $225, \S 1^{\circ}$, VII, da CF, que veda prática que acabe por submeter os animais à crueldade, como é o caso da conhecida "farra do boi".

A partir desta afirmação é possível afirmar que poderiam ser toleradas práticas cruéis e dolorosas contra animais, ainda que estejam apoiadas em critérios culturais.

Porém, ao mesmo tempo em que aperfeiçoa os dispositivos legais a favor da proteção aos animais, o Congresso Nacional aprovou duas leis em favor da prática dos rodeios e vaquejadas: a Lei n. 10.220/01, que equiparou o peão de rodeio e o vaqueiro a atletas profissionais, referindo-se às provas de laço, montarias e vaquejadas como "práticas esportivas", e posteriormente, a Lei 10.519/02, conhecida como a lei federal dos rodeios, que dispõe sobre cuidados sanitários relacionados à modalidade (LEVAI, 2002).

0 artigo $4^{\circ}$ da Lei 10519/02 (BRASIL, 2002), afirma que

os apetrechos técnicos utilizados nas montarias, bem como as características do arreamento, não poderão causar injúrias ou ferimentos aos animais e devem obedecer às normas estabelecidas pela entidade representativa do rodeio, seguindo as regras internacionalmente aceitas.

0 artigo em questão, apesar de afirmar que não poderá haver injúrias aos animais, deixa a critério das entidades representativas dos rodeios regulamentar as normas aplicáveis às suas práticas, o que pode gerar conflitos jurídicos no tocante à proteção dos animais, já que possivelmente o espetáculo será privilegiado, em detrimento dos cuidados relacionados aos animais.

Ainda analisando 0 artigo $4^{\circ}$ da Lei 10519/02 (BRASIL, 2002),

$\S 1^{\circ}$ As cintas, cilhas e as barrigueiras deverão ser confeccionadas em lã natural com dimensões adequadas para garantir o conforto dos animais.
$\S 3^{\circ}$ As cordas utilizadas nas provas de laço deverão dispor de redutor de impacto para o animal.

Estes dois parágrafos deixam claro que a integridade dos animais utilizados nos rodeios não está sendo protegida em sua totalidade. Por mais que sejam confeccionadas em lã natural e com dimensões "adequadas", instrumentos como cintas, cilhas e barrigueiras não trazem conforto aos animais. 0 mesmo se aplica às cordas utilizadas nas provas de laço; mesmo que elas disponham de redutores de impacto, isto não será suficiente para evitar dor e sofrimento nos animais, já que estes continuarão sendo laçados e arremessados ao chão de forma violenta.

Porém, ao tratar dos profissionais peões de rodeio, a lei 10220/01 claramente se preocupa em the conferir proteção, quando, em seu artigo $2^{\circ}, \S 1^{\circ}$ determina que,

\begin{abstract}
é obrigatória a contratação, pelas entidades promotoras, de seguro de vida e de acidentes em favor do peão de rodeio, compreendendo indenizações por morte ou invalidez permanente no valor mínimo de cem mil reais, devendo este valor ser atualizado a cada período de doze meses contados da publicação desta Lei, com base na Taxa Referencial de Juros - TR (BRASIL, 2001)
\end{abstract}

Esta determinação demonstra uma preocupante inversão de valores, onde é preservada a integridade física dos peões de rodeio, ao mesmo tempo em que se permitem "lacunas" para a continuação dos maus tratos aos animais. Para exemplificar esta afirmação, faz-se uso da afirmação de Hansen (2008, p.8),

como grande parte da legislação ambiental brasileira tocante à fauna (Lei sobre caça, pesca etc), a Lei de Rodeios (Lei 10.519 de 17 de julho de 2002) também atua como um meio regulador de atividades e não protetor e garantidor de direitos aos animais utilizados nestes eventos. Este dispositivo é completamente vago, ineficaz na proteção aos animais e ainda dá liberdades aos organizadores dos rodeios de definirem o que é crueldade de acordo com suas próprias convicções e regras internacionalmente aceitas. 


\subsection{MANIFESTAÇÕES CULTURAIS OU MAUS TRATOS?}

Os defensores dos rodeios e das vaquejadas comumente se amparam nos dispositivos legais de proteção às manifestações culturais para positivar suas ações.

No caso da vaquejada, seus defensores alegam que ela é um elemento arraigado em nossa cultura, amparada pelo disposto no art. $215, \S 1^{\circ}$, da Constituição Federal, que diz que "o Estado garantirá a todos o pleno exercício dos direitos culturais e acesso às fontes da cultura nacional, e apoiará e incentivará a valorização e a difusão das manifestações culturais" e que "o Estado protegerá as manifestações das culturas populares, indígenas e afro-brasileiras, e das de outros grupos participantes do processo civilizatório nacional", além de servir de atrativo para o incremento do turismo, movimentando a economia local, com a geração de vários empregos sazonais (SILVA, 2007, p. 29)

Em se tratando da vaquejada são inegáveis suas raízes culturais, principalmente na região nordeste, 0 que, de certa forma, a ampararia no disposto no art. 215 , $\S 1^{\circ}$, da Constituição Federal. Porém, deve prevalecer o entendimento de que a proteção a práticas esportivas não podem ser sobrepostas ao bem estar e integridade física dos animais.

Já no caso do rodeio não se aplica o precedente de manifestação cultural, pelo menos no Brasil, já que se trata de uma modalidade surgida nos Estados Unidos, que foi, tão somente, importada para o Brasil, sem que aqui houvesse qualquer noção prévia ou esboço dessa atividade. Ou seja, a situação do rodeio torna-se ainda mais grave, a partir do momento em que nem ao menos o elemento cultural está presente para "respaldar" a sua prática (SOUZA, 2008).

Outro argumento dos que são favoráveis aos rodeios e vaquejadas indica que eles são atividades tradicionais no meio rural brasileiro, e que tem gerado empregos, renda e movimentado a economia de várias cidades. Entre os políticos, as explicações iam da garantia de realização de um evento que já estava absolutamente incorporado na agenda dos brasileiros até à defesa dos direitos trabalhistas dos profissionais do rodeio (PEREIRA DA COSTA, 2003)

Se argumentos de ordem cultural não se sustentam para que se continue permitindo os maus tratos a animais, o mesmo se aplica a argumentos baseados em aspectos econômicos ou que visem apenas o lucro financeiro.

A Constituição Federal de 1988 afirma em seu o art. $225, \S 1^{\circ}$, VII, que incumbe ao Poder Público proteger a fauna e a flora, vedadas, na forma da lei, as práticas que coloquem em risco sua função ecológica, provoquem a extinção de espécies ou submetam os animais à crueldade (BRASIL, 1988). 0 termo "crueldade" aqui pode ser aplicado em sentido amplo, no qual se enquadram o rodeio e a vaquejada.

A natureza cruel das vaquejadas, por exemplo, pode atestada já nas suas regras, como bem aponta Silva (2007, p. 34):

\begin{abstract}
onde se lê que "numa pista de 160 metros de comprimento com variações em sua largura, demarca-se uma faixa aonde os bois deverão ser derrubados. Dentro deste limite será válido o ponto, somente quando o boi, ao cair, não queimar a cal (material usado para demarcar as faixas), isso acontece quando o boi é puxado dentro da faixa e mostra as quatro patas antes de levantar-se ainda dentro das faixas de classificação. 0 boi que ficar de pé, em cima da faixa receberá nota zero de imediato" e que "o boi será julgado de pé. Deitado, somente caso não tenha condições de levantar-se"
\end{abstract}

Outro exemplo, também apontado por Silva (2007, p. 34), diz respeito ao fato de ser comum caudas de bois serem arrancadas durante a prática da vaquejada

conforme disposto no regulamento do "IV Potro do Futuro \& IV Campeonato Nacional ABQM - Vaquejada”, realizado na cidade de Campina Grande - PB:

"Regulamento do IV Potro do Futuro ABQM de Vaquejada

Disposições Gerais para o IV Potro do Futuro de Vaquejada 
$[\ldots]$

E - Caso o rabo ou a maçaroca do boi parta-se no momento da queda, e o boi não cair, o mesmo será julgado de acordo com os critérios abaixo, tanto na fase de classificação como na fase final:

- Primeira quebra: caso o boi não caia, a dupla competidora terá direito a um boi extra;

- Segunda quebra: o boi será julgado, caindo ou não; a dupla competidora não terá direito a boi extra;

- Terceira quebra: a dupla competidora terá nota zero, independente do julgamento do boi.

Como são levados ao chão de forma bruta constantemente, os bois usados na vaquejada tendem a sofrer luxações e hemorragias internas devido ao tombo, além de sofrerem intenso stress, em decorrência do medo de seus agressores durante as perseguições nas provas (MARASCHIN; ITAQUI, 2010).

Já foi possível avaliar, também, que os equinos de vaquejada apresentam alterações físicas, bioquímicas e hematológicas em decorrência do exercício e do estresse a que são submetidos, além da falta de uma rotina de treinamento adequado e às condições ambientais inóspitas dos parques de vaquejada. Os cavalos são extremamente exigidos e realizam esforço físico de curta duração, mas de alta intensidade durante a derrubada do boi (LOPES et. al, 2009).

No caso do rodeio, o uso do sedém, juntamente com as esporas, aparenta ser o maior causador de dor e sofrimento aos animais, como afirma Souza (2008, p. 2):

com efeito, o sedém é uma tira de crina de animal que é fortemente amarrada no flanco inguinal (virilha) dos animais. Do uso do sedém resulta a compressão dos ureteres dos animais (canais que ligam os rins à bexiga), além da compressão do prepúcio, do pênis e do escroto que fazem o animal saltar desesperadamente, a fim de livrar-se do incômodo e da dor. As esporas, com formato rombo ou pontiagudo, acopladas às botas dos peões, são utilizadas para golpear o animal em locais como o baixo-ventre, o pescoço e a cabeça, podendo inclusive até cegá-los, e, em conjunto com o sedém e demais instrumentos, levam o animal a saltar de forma mais intensa, devido ao grande sofrimento que the é causado.
Outro artifício bastante utilizado no rodeio para causa dor ao animal é peiteira, como destaca Souza (2008, p. 2-3)

as peiteiras consistem em cordas de couro fortemente atadas e enrijecidas em redor do peito dos animais por detrás de suas axilas. As peiteiras causam uma sensação de asfixia no animal, provocando-lhe medo e liberação de substâncias que alteram seu comportamento. Nas peiteiras são acrescentados sinos, também chamados de polacos, os quais produzem um barulho altamente angustiante ao animal, ficando ainda mais perturbador a cada corcoveio deste. Aliás, vale ressaltar que a irritação causada pelos polacos aos touros é tão intensa, que os próprios admiradores e participantes de rodeios a admitem, definindo os polacos como: "sinos de metal colocados no touro para irritá-lo". o objetivo deste complexo de artifícios é provocar os pulos e corcoveios do animal, com maior intensidade, devido às fortes dores em seu tronco e às perturbações provocadas no seu sistema nervoso.

O mesmo autor chama a atenção para artifícios, que não são perceptíveis aos espectadores, utilizados antes de os animais entrarem na arena de rodeios,

que, além de provocarem mais saltos e corcoveios dos animais, não são percebidos claramente pelos espectadores. Vale destacar: o uso de choques elétricos e mecânicos, que são aplicados nos órgão genitais do animal; a utilização de objetos pontiagudos, tais como pregos, pedras, alfinetes e arames em forma de anzol colocados sob a sela do animal; a inserção de terebintina e pimenta no corpo do animal, para que fiquem ainda mais enfurecidos; a disposição de substâncias abrasivas, que ao entrarem em contato com cortes e outros ferimentos no corpo do animal causam uma sensação de ardor insuportável; a aplicação de golpes e marretadas na cabeça do animal que costumam produzir convulsões no animal, sendo métodos bastante utilizados quando o animal já está velho ou cansado, com o objetivo de provocar sua morte; e, a prática da descorna, que é a retirada, sem anestésico, dos chifres do touro com a utilização de um serrote, para a realização de determinadas provas, provocando ainda mais sangramentos e dor (SOUZA, 2008, p. 3).

Nóbrega Neto (2008) corrobora com a ideia da presença de maus tratos a animais nas duas modalidades, ao afirmar que animais usados em "esportes", 
como bovinos e equinos de rodeios e de vaquejadas, e os equinos de corridas e hipismo estão sujeitos à diminuição do seu bem-estar, já que sofreriam estresse não só durante as provas, mas, também, durante os transportes entre um lugar e outro de competição.

Nesta mesma linha de raciocínio, ao comentar a prática dos rodeios, Hansen (2008) afirma que descrever como os animais são preparados para essas competições (que muito mais se pareceriam com circo de horrores) é agonizante, já que, após ficarem em condições de espaço mínimo, incapazes de se mover, eles são levados à arena onde deve começar o "show" e, posteriormente, ficam esperando em uma espécie de "antessala do terror", onde o peão monta em cima do animal e este sofre uma grande quantidade de cho- ques e chutes para ficar mais irritado. O autor afirma, ainda, que a parte mais intrigante de toda essa seção de crueldade é que como é considerado um esporte, ocorrem treinos praticamente diários, todos longe da deficiente fiscalização existente, onde as mais perversas crueldades podem ser cometidas.

Tanto a farra do boi quanto as rinhas ou brigas de galo, os rodeios ou vaquejadas, entendidas como manifestações culturais abrigadas pelo artigo 225, caput e parágrafo $1^{\circ} \mathrm{da} C \mathrm{~F} / 88$, confrontam-se com a proibição de tratamento cruel contra os animais (artigo 225, parágrafo $1^{\circ}$, VII, da CF/88). E, desta forma, entende-se que o meio ambiente natural não pode ser deteriorado, ainda que existam fortes argumentos de ordem cultural (MARASCHIN; ITAQUI, 2010)

\section{CONSIDERACÕ̃ES FINAIS}

Baseado nos argumentos expostos é possível chegar à conclusão de que, apesar de regulamentadas por leis específicas, o rodeio e a vaquejada são práticas que vão de encontro às legislações de proteção contra maus tratos a animais.

É preciso reavaliar a forma como a fauna é tratada na legislação ambiental, já que não mais se admitem "lacunas" que permitam aos organizadores de eventos, como o rodeio e a vaquejada, se sentirem amparados legalmente para continuar cometendo maus tratos e violência contra os animais que utilizam.

É aceitável, de certa forma, o argumento de que a prática do rodeio e da vaquejada possui origens culturais que precisam ser respeitadas, porém é necessário que seja estabelecido um limite, no qual se verifique até que ponto esta liberdade cultural abriga práticas cruéis contra os animais.

\section{REFERÊNCIAS}

AIRES, Francisco Jânio Filgueira. 0 espetáculo do “cabra-macho": um estudo sobre os vaqueiros nas vaquejadas no Rio Grande do Norte. 2008. 183p. Dissertação (Mestrado em Antropologia) - Universidade

BRASIL. Constituição da República Federativa do

Brasil. Brasília. Disponível em: < http://www.planalto. gov.br/ccivil_03/constituicao/constitui\%C3\%A7ao. htm>. Acesso em: 10 mar. 2012

Federal do Rio Grande do Norte, Natal. 
BRASIL. Lei n. 9605, de 12 de fevereiro de 1998. Brasília. Dispõe sobre as sanções penais e administrativas derivadas de condutas e atividades lesivas ao meio ambiente, e dá outras providências.

Disponível em: < http://www.planalto.gov.br/ccivil_03/leis/L9605.htm > Acesso em: 10 mar. 2012

BRASIL. Lei n. 10220, de 11 de abril de 2001. Brasília. Institui normas gerais relativas à atividade de peão de rodeio, equiparando-o a atleta profissional.

Disponível em: <http://www.planalto.gov.br/ccivil_03/Leis/LEIS_2001/L10220.htm> Acesso em: 11 mar. 2012

BRASIL. Lei n. 10519, de 17 de julho de 2002. Brasília. Dispõe sobre a promoção e a fiscalização da defesa sanitária animal quando da realização de rodeio e dá outras providências.

Disponível em: <http://www.planalto.gov.br/ccivil_03/ Leis/2002/L10519.htm>. Acesso em: 11 mar. 2012

CADAVEZ, Lília Maria Vidal de Abreu Pinheiro. Crueldade contra os animais: uma leitura transdisciplinar à luz do sistema jurídico brasileiro. Direito \& Justiça, Porto Alegre, v. 34, n. 1, jan/jun. 2008, p. 88-120.

FIORILLO, Celso Antonio Pacheco. Curso de Direito Ambiental Brasileiro. 7. ed. São Paulo: Saraiva, 2006, 117p.

HANSEN, Thiago Freitas. Ineficácia da Lei de Rodeios e a Cultura humana sobrepondo-se ao Direito dos Animais. In: Congresso Mundial De Bioética e Direito Animal, Salvador, 2008.

LEVAI, Laerte Fernando. Crueldade consentida: a violência humana contra os animais e o papel do Ministério Público no combate à tortura institucionalizada. Fórum Nacional de Proteção e Defesa Animal, Brasil, 2002. Disponível em:

<http://www.forumnacional.com.br/crueldade_consentida.pdf>. Acesso em: 1 mar. 2012.
LOPES, Kátia Regina Freire; BATISTA, Jael Soares; DIAS, Regina Valéria da Cunha; SOTO-BLANCO, Benito. Influência das competições de vaquejada sobre os parâmetros indicadores de estresse em equinos. Ciência Animal Brasileira, v. 1,n. 2, abr./jun., 2009, p. 538-543.

MARASCHIN, Claudio; ITAQUI, Cintia. Os direitos dos animais e o judiciário: uma proposta de estudo. Revista Estudos Legislativos, v. 3, 2009.

MENEZES, Sonia de Souza Mendonça; ALMEIDA, Maria Geralda. Vaquejada: a pega de boi na caatinga resiste no sertão sergipano. Vivência, n. 34, 2008, p. 181-193.

NEVES, Isadora Ferreira. Da inconstitucionalidade da prática de rodeios. Juspendia, 10 março 20028. Disponível em: <http://www.iuspedia.com.br>. Acesso em: 11 maio 2012.

NOBREGA NETO, Pedro Isidro. Dor, seiscência e bem estar em animais: grandes animais. Ciência Veterinária nos Trópicos, Recife, v. 11, n. 1, nov., 2009.

PEREIRA DA COSTA, Simone. Esporte e Paixão: o processo de regulamentação dos rodeios no Brasil. Movimento, Porto Alegre, v. 9, n. 2, mai./ago., 2003, p. 71-87.

PIMENTEL, Giuliano Gomes de Assis. Localismo e Globalismo na esportivização do rodeio. Revista Brasileira Ciência Esporte, Campinas, v. 28, n. 1, set. 2006, p. 91-104.

SILVA, Thomas de Carvalho. Vaquejadas: manifestações das culturas ou crime de crueldade e maus tratos contra os animais? 2007. 50p. Monografia

(Graduação em Direito) - Centro de Ciências Jurídicas da Universidade de Fortaleza, Fortaleza.

SOUZA, Gabriel Campos. Os rodeios e a Lei 10519/02: retrocesso social e desconformidade com a Constituição Federal de 1988. In: Congresso Mundial de Bioética e Direito Animal, Salvador, 2008, p. 1-16. 
1 Biólogo com experiência em Biologia Marinha, Conservação e PreserAvaliado em: 28 de novembro de 2013 Aceito em: 20 de novembro de 2013

vação de Mamíferos Aquáticos e no Ensino de Ciências e Biologia. BioméUniversidade Tiradentes. Possui MBA em Gestão e Direito Ambiental pela Facinter/PR. igor_fla@hotmail.com 